\title{
Yumurta Kabuğundan Alınan Akustik Sinyalin Dalgacık Paket Dönüşümü ve Entropiye Dayalı Olarak İşlenmesi ve Yapay Sinir Ağlarıyla Çatlağın Belirlenmesi
}

\section{Processing the Acoustic Signal Received from the Eggshell Based on Wavelet Packet Transformation and Entropy and Detecting the Crack with Artificial Neural Networks}

\author{
Zekeriya Balc1 $^{1 *}$, Mehmet Yumurtac1 ${ }^{2}$, İsmail Yabanova ${ }^{3}$, Semih Ergin $^{4}$ \\ Geliş / Received: 27/12/2020 \\ Revize / Revised: 15/02/2021 \\ Kabul / Accepted: 22/02/2021
}

$\overline{\text { ÖZ }}$

Endüstride birçok üründe ve evlerimizde, vitaminler ve mineraller bakımından zengin olmasından dolayı yumurta yaygın olarak tüketilmektedir. Artan ihtiyacın hızlı bir şekilde karşılanması için tavuk çiftliklerinde yumurtaların toplanması, ağırlıklarına göre sınıflandırılması, sağlam/çatlak olanların ayrılması, paketlenmesi vb. işlemler için otomasyona geçiş yapılmıştır. Kabuğun çatlak olması durumunda içerisine zararlı mikroorganizmalar kolaylıkla girebileceği gibi yumurta içinin havayla temasından dolayı kısa sürede bozulmasına yol açacaktır. Çatlaklar gözle görülebilecek kadar büyük olabildiği gibi bazen de mikro boyutta olmakta insan gözüyle tespit edilememektedir. $\mathrm{Bu}$ çalışmada yumurta kabuğunun çatlak/sağlam olması durumunun sinyal işleme ve makine öğrenme tabanlı tespiti gerçekleştirilmiştir. Mekanik sistem vasıtasıyla kabuğa yapılan darbe neticesindeki oluşan akustik sinyal sistemdeki mikrofonla $50 \mathrm{kHz}$ örnekleme frekansında 0.2 sn süresince kayıt altına alınmaktadır. Kabuğu sağlam ve çatlak olan ayrı ayrı 50 yumurta verisi düzenekle kayı altına alınıp veri seti oluşturulmuştur. Yumurta kabuğuna darbenin uygulanma anından sönümlenene kadarki zamanın tespiti için $0.74 \mathrm{~V}$ eşik değeri kullanılıp bu değerden sonraki 680 veri alınmıştır. Bu verilere db4 ana dalgacığı ile 2. seviyeden Dalgacık Paket Dönüşümü (DPD) uygulanarak farklı frekanslı detay ve yaklaşım bileşenleri çıkartılmıştır. Her bir bileşenin entropi değeri hesaplanarak $1 \mathrm{x} 4$ boyutunda özellik vektörü elde edilmiştir. Çıkartımı yapılan özellik vektörünün yumurta kabuğundaki çatlağın tespitindeki etkinliğini belirlemek için Yapay Sinir Ağı (YSA) kullanılmıştır. \%100 başarım elde edilmiş olup bir yumurtanın kabuk çatlak/sağlam belirleme süresi yaklaşık olarak 0.216 sn’dir.

Anahtar Kelimeler- Çatlak, Entropi, Dalgacık Paket Dönüşümü, Sinyal İşleme, Yapay Sinir Ăgları

\footnotetext{
ABSTRACT

Eggs are widely consumed in many products industry and homes as they are rich in vitamins and minerals. In order to meet increasing need quickly, automation has been made in chicken farms for processes, such as collecting

1*Sorumlu yazar iletişim: balcizekeriya29@gmail.com (https://orcid.org/0000-0002-1389-1784)

Elektronik ve Otomasyon Bölümü, Van Yüzüncü Yıl Üniversitesi, Çaldıran Meslek Yüksekokulu, Van, Türkiye

2İletișim: mehmetyumurtaci@aku.edu.tr (https://orcid.org/0000-0001-8528-9672)

Elektrik-Elektronik Mühendisliği Bölümü, Afyon Kocatepe Üniversitesi, Teknoloji Fakültesi, Afyon, Türkiye

IIletişim: iyabanova@gmail.com (https://orcid.org/0000-0001-8075-3579)

Mekatronik Mühendisliği Bölümü, Afyon Kocatepe Üniversitesi, Teknoloji Fakültesi, Afyon, Türkiye

3İletişim: sergin@ogu.edu.tr (https://orcid.org/0000-0002-7470-8488)

Elektrik-Elektronik Mühendisliği Bölümü, Eskișehir Osmangazi Üniversitesi, Mühendislik-Mimarlık Fakültesi, Eskişehir, Türkiye
} 
eggs, weight classifying, separating cracked, and packing. If shell is cracked, harmful microorganisms can easily enter into it, and egg will deteriorate in a short time due to contact with air. Cracks can be large enough to be visible to naked eye, and sometimes they are micro-sized and cannot be detected by human eye. In this study, detection of cracked eggshell based on signal processing and machine learning was carried out. Acoustic signal generated as a result of impact made to shell by means of mechanical system was recorded for 0.2 seconds at a sampling frequency of $50 \mathrm{kHz}$ with microphone. Separately, 50 eggs data with intact and cracks shells were recorded with system and data set were created. Threshold value of $0.74 \mathrm{~V}$ was used to determine time from moment of impact to egg shell to damping, and 680 data were taken after this value. The detail and approximation components with different frequencies were extracted by applying Wavelet Packet Transform (WPT) from 2nd level with db4 main wavelet. By calculating entropy value of each component, $1 \times 4$ feature vector was obtained. Artificial Neural Network (ANN) was used to determine efficiency of extracted feature vector in detecting crack egg shell. $100 \%$ performance was achieved and an egg's shell crack detection time was determined in approximately 0.216 seconds.

\section{Keywords-Crack, Entropy, Wavelet Packet Transform, Signal Processing, Artificial Neural Networks}

\section{GİRIŞ}

Yumurta, zengin besin içeriklerinden ve ucuz bir gıda olmasından dolayı insanlar tarafından günlük beslenmede tercih edilen ve tüketimi giderek artış gösteren besin kaynaklarından birisi olmuştur [1]. Ancak yumurtanın kabuğunda üretimden pazara ulaşıncaya kadar kırık ve çatlak gibi hasarlar oluşabilmektedir. Bu hasarlar sonucunda işletmelerde ve yumurta endüstrisinde önemli bir sorun teşkil etmekle birlikte önemli ekonomik kayıplara neden olabilmektedir [2,3]. Yumurta kabuğunda oluşabilecek çatlaklar yumurtayı zararlı mikro organizmalara karşı savunmasız hale getirebilmektedir. Bakteri bulaşmış bir yumurta insan sağlığını tehdit edebilmekle birlikte gıda güvenirliğini ortadan kaldırmaktadır [4]. Çatlak yumurtadan kaynaklanabilecek bu olumsuzlukların giderilmesi veya en aza indirilmesi amacıyla, çatlak yumurtaların üretim aşamasında tespit edilerek ayrıştırılması önem arz etmektedir.

Yumurta çatlaklarının tespiti için yapılan çalışmaların, akustik sinyal analizi ve bilgisayarlı görü yöntemleri üzerine yoğunlaştı̆̆ görülmektedir.

Bilgisayarlı görü yöntemleri basit yapısı, bakım maliyetleri ve çevre gürültüsünden etkilenmediği için çatlak yumurta tespiti çalışmalarında da kullanılmıştır. Bilgisayarlı görü yöntemlerinde yumurta bir ışık kaynağı tarafından aydınlatılarak yumurta yüzeyindeki kusurların ortaya çıkarılması sağlanır. Daha sonra görüntü kamera ile alınarak ardından çeşitli görüntü işleme yöntemleri ve örüntü tanıma metotları ile çatlaklar tespit edilmeye çalışılmıştır. Önceki çalışmalar göstermiştir ki, gözle görülebilen çatlaklarda bilgisayarlı görü ile yumurta kabuğundaki çatlaklar \%90 üzeri bir başarımla tespit edilebilmiştir [5-10]. Ancak bilgisayarlı görü yönteminde yumurta yüzeylerinin düzensizliği ve ışık kaynağının ayarı yumurta kabuğundaki çatlakların tespitinde sorun teşkil ettiği, ayrıca bu yöntemlerin yumurta kabuğundaki mikro çatlakları tespit etmede yetersiz kaldığı rapor edilmiştir [11]. Belirtilen problemin çözümü için yumurtaya kapalı bir kap içerisinde negatif basınç uygulanması sonucunda mikro çatlak bölge açılarak çatlak alanın görünürlüğü arttırılması sonucu uygulanan yöntemler ile çatlak tespitinde \% 100'e kadar ulaşıldığı rapor edilmiştir [12-15]. Sunulan çalışmalar, negatif basınç sonucu mikro çatlağın belirginleştirilerek tespit edilmesinde başarımın yüksek olmasına rağmen bu sistemlerin karmaşık yapısı, online tespit ve endüstriye uygulanabilirliği bakımından çekinceler oluşturmaktadır.

Akustik sinyal analizi yönteminde, yumurtaya zarar vermeyecek bir şiddette yumurta kabuğuna uygulanan mekanik etki sonucu oluşan akustik sinyallerin analizi ile çatlak tespit edilmeye çalışılmıştır. Bu yöntem temelde, akustik cevap sinyalinin alınması, özellik çıkarımı ve seçiminin ardından tanıma işleminden oluşmaktadır. Son çalışmaların tanıma sürecinde sınıflandırma algoritması geliştirilmesi üzerine yoğunlaştı̆̆ görülmüsstür. Yumurta kabuğundaki çatlakların tespiti için akustik sinyal analizi üzerine, Bulanık Mantık [16], Destek Vektör Veri Tanımlaması [17], Destek Vektör Makinaları [18], Lineer Ayrımcıllk Analizi [19], YSA [20, 21] ve birçok yöntem uygulanmıştır [22-25]. Uygulanan bu yöntemler neticesinde yumurta kabuğundaki çatlakların tespitinde başarımın \% 98.9'a kadar ulaştığı, sistem performansı ve hızının pratikte uygulanabilirliği için iyileştirilmesi gerektiği rapor edilmiştir. 


\begin{tabular}{|c|c|c|}
\hline & $\begin{array}{l}\text { BŞEÜ Fen Bilimleri Dergisi } \\
8(1), 125-135,2021\end{array}$ & $\begin{array}{r}\text { BSEU Journal of Science } \\
\text { https://doi.org/10.35193/bseufbd.847763 }\end{array}$ \\
\hline $\begin{array}{l}\text { BilECEKSEYHEDEBALI } \\
\text { ONIVERSITESI }\end{array}$ & & 2458-7575 (https://dergipark.org.tr/tr/pub/bseufbd) \\
\hline
\end{tabular}

Bu çalışma, yumurta kabuğuna uygulanan mekanik bir etki sonucunda oluşan akustik sinyal kullanılarak kabuğun çatlak/sağlam olması durumunun belirlenmesi üzerinedir. Akustik sinyal mikrofon yardımıyla $50 \mathrm{kHz}$ örnekleme frekansında 10.000 veri olarak kayıt altına alınmıştır. Kabuğa uygulanan darbeden itibaren sönümlenme anına kadarki verileri tespit etmek için $0.75 \mathrm{~V}$ eşik değerinin üzerine çıkılmasından sonraki 680 veri kullanılmıştır. $\mathrm{Bu}$ veriye DPD uygulanarak farklı frekanslı bileşenleri tespit edilmiştir. Her bir bileşenin entropi değeri hesaplanarak 1x4 boyutunda özellik vektörü elde edilmiştir. Yumurta kabuğunun sağlam olması durumunda YSA' nın çıkış etiketi 1 iken çatlak olması durumunda 0 olarak belirlenmiştir. 50 sağlam ve 50 çatlak kabuğa sahip yumurta verisi kullanılarak YSA eğitilmiştir. 100 adet veriden rast gele olarak seçilen 80 adedi ağın eğitimi, 10 adedi eğitilen ağın değerlendirilmesinde ve son olarak geriye kalan 10 adedi ise test işleminde kullanılmıştır. Ağın çıkışında kabuğun sağlam olması durumunda 1 bilgisi alınırken çatlak olması durumunda 0'a yakın bir değer alınmaktadır. Ağ çıkış etiketinin 0 olması için bir eşik değer (1e-6) kullanılmıştır. Harici olarak alınan 16 adet yumurta verisi ile ekstra olarak sınıflandırma yapılmış olup tüm veriler için \%100 başarım elde edilmiştir. Bu makalede, öncelikle, literatürde daha önce yer almayan, kendi içerisinde kararlı ve istikrarlı deneysel çalışmaların sonucu elde edilmiş bir veri tabanının araştırmacıların bilgisine ve kullanımına sunulması gerçekleştirilmiştir. Bu veri tabanı kullanılarak yumurta kabuğundaki çatlakların belirlenmesinde öne sürülen DPD ve entropiye dayalı öznitelik vektörleri sayesinde $1 \mathrm{x} 4$ vektör boyutuyla $0.216 \mathrm{sn}$. gibi oldukça kısa bir sürede ve epeyce yüksek bir doğruluk oranıyla yumurta çatlağı tespit işlemi yürütülmüştür.

\section{MATERYAL VE METOT}

Uygulamada geliştirilen deneysel düzenek güç kaynağı, işlemsel yükselteç ve kontrol devresi, CompactRIO (cRIO), verilerin toplanması analiz edilmesi, görselleştirilmesi için yazılım ve bilgisayardan oluşmaktadır. Şekil 1'de uygulama için geliştirilen sistemin blok şeması verilmiştir. Sonraki bölümlerde bileşenler detaylı olarak anlatılmıştır.

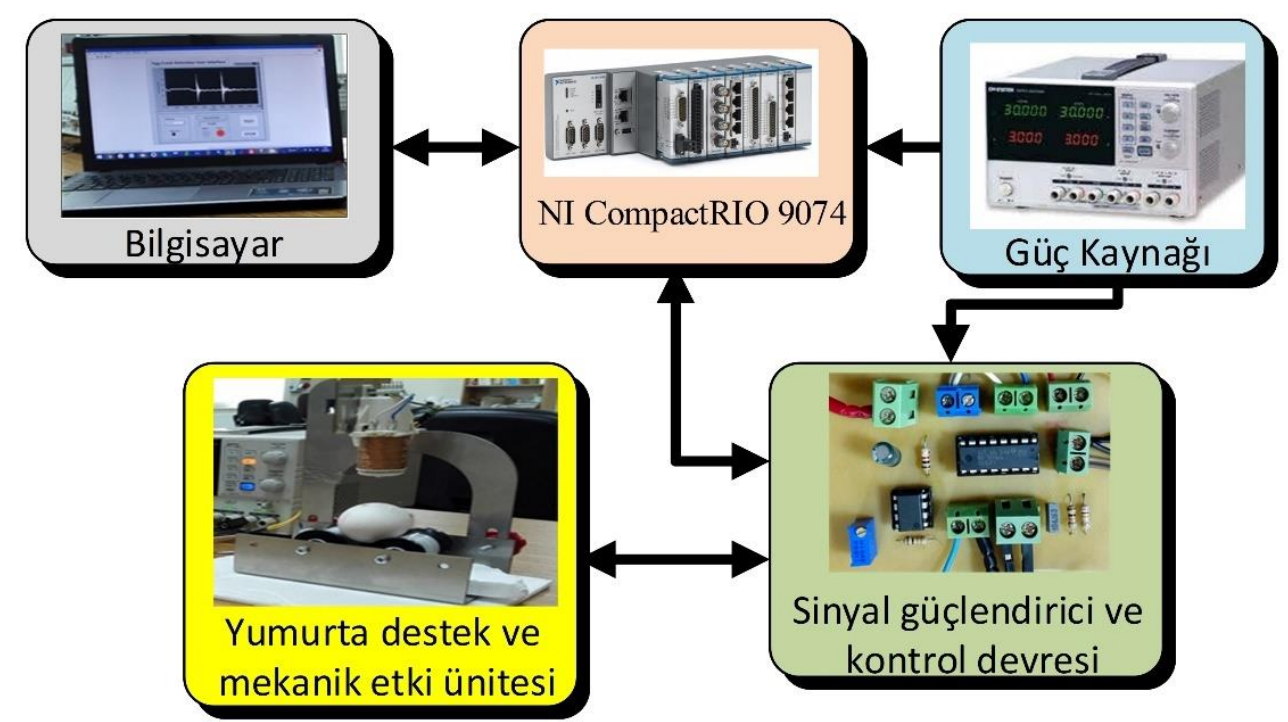

Şekil 1. Sistemin blok şeması 


\begin{tabular}{|c|c|c|}
\hline & $\begin{array}{l}\text { BŞEÜ Fen Bilimleri Dergisi } \\
8(1), 125-135,2021\end{array}$ & $\begin{array}{r}\text { BSEU Journal of Science } \\
\text { https://doi.org/10.35193/bseufbd.847763 }\end{array}$ \\
\hline $\begin{array}{l}\text { BilECEKSEYHEDEBALI } \\
\text { ONIVERSITESI }\end{array}$ & & 2458-7575 (https://dergipark.org.tr/tr/pub/bseufbd) \\
\hline
\end{tabular}

\section{A. CompactRIO}

CompactRIO National Instruments (NI) firması üretimi modüler birimler ile uygulamaya yönelik düzenlenebilir endüstriyel kontrolördür [26]. Bu çalışmada cRIO 9074 ile birlikte NI-9215 analog giriş modülü ve NI-9375 dijital giriş çıkış modülü kullanılmıştır. cRIO’ya ait teknik özellikleri aşağıda verilmiştir.

- +19V DC ile 30V DC arası çalışma gerilimi

- $400 \mathrm{MHz}$ işlemci hızı

- $256 \mathrm{MB}$ dahili hafiza

- Xilinx Spartan-3 2M FPGA

- Ethernet ve RS232 haberleşme desteği

- 8 adet modüler birim

\section{B. Yumurta Destek ve Mekanik Etki Ünitesi}

Yumurtanın konumlandırılacağı yumurta destek ünitesi ve mekanik etki ünitesi Şekil 2'de verilmiştir. Bu ünite ile makaralar üzerine konumlandırılan bir adet yumurtaya mekanik bir etki uygulanarak bu etki sonucunda oluşan ses sinyalleri bir mikrofon yardımı ile alınmaktadır. Mekanik etki ünitesi içi boş bir boru şeklinde dışı bobin ile sarılmış dış kısım ve dış kısmın içinde boru şeklindeki hareketli iç kısımdan oluşmaktadır. Bu hareketli kısım yumurtanın kabuğuna zarar vermeyecek bir çarpma ile akustik sinyallerin oluşturulmasını sağlamaktadır ve bu olay Şekil 3'de tasvir edilmiştir.

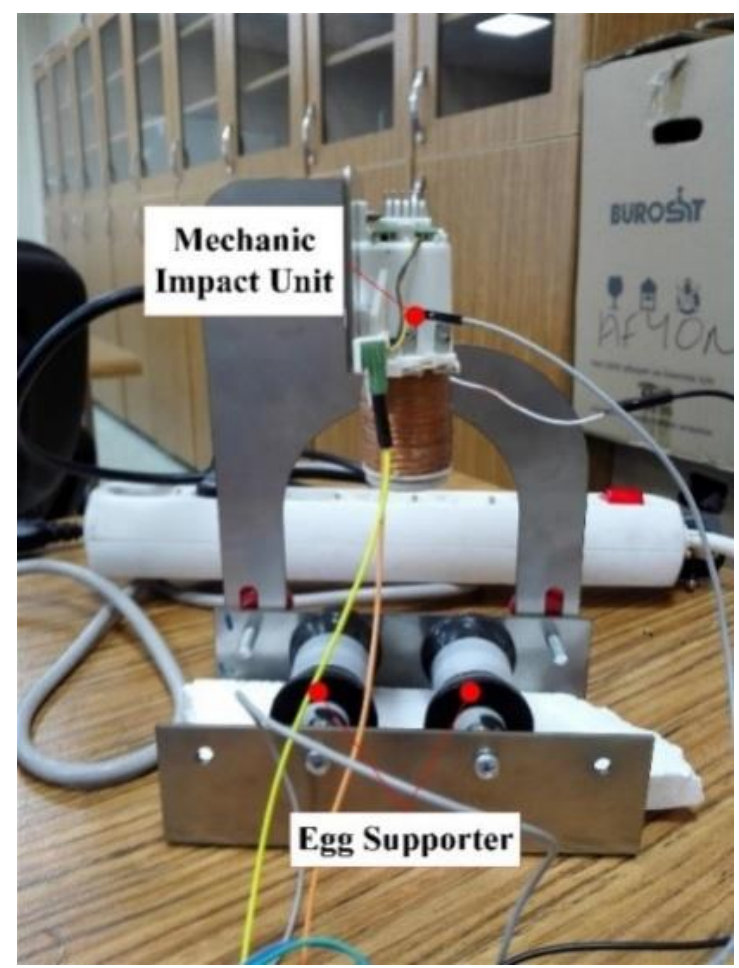

Şekil 2. Yumurta destek ünitesi ve mekanik etki ünitesi genel görünümü 

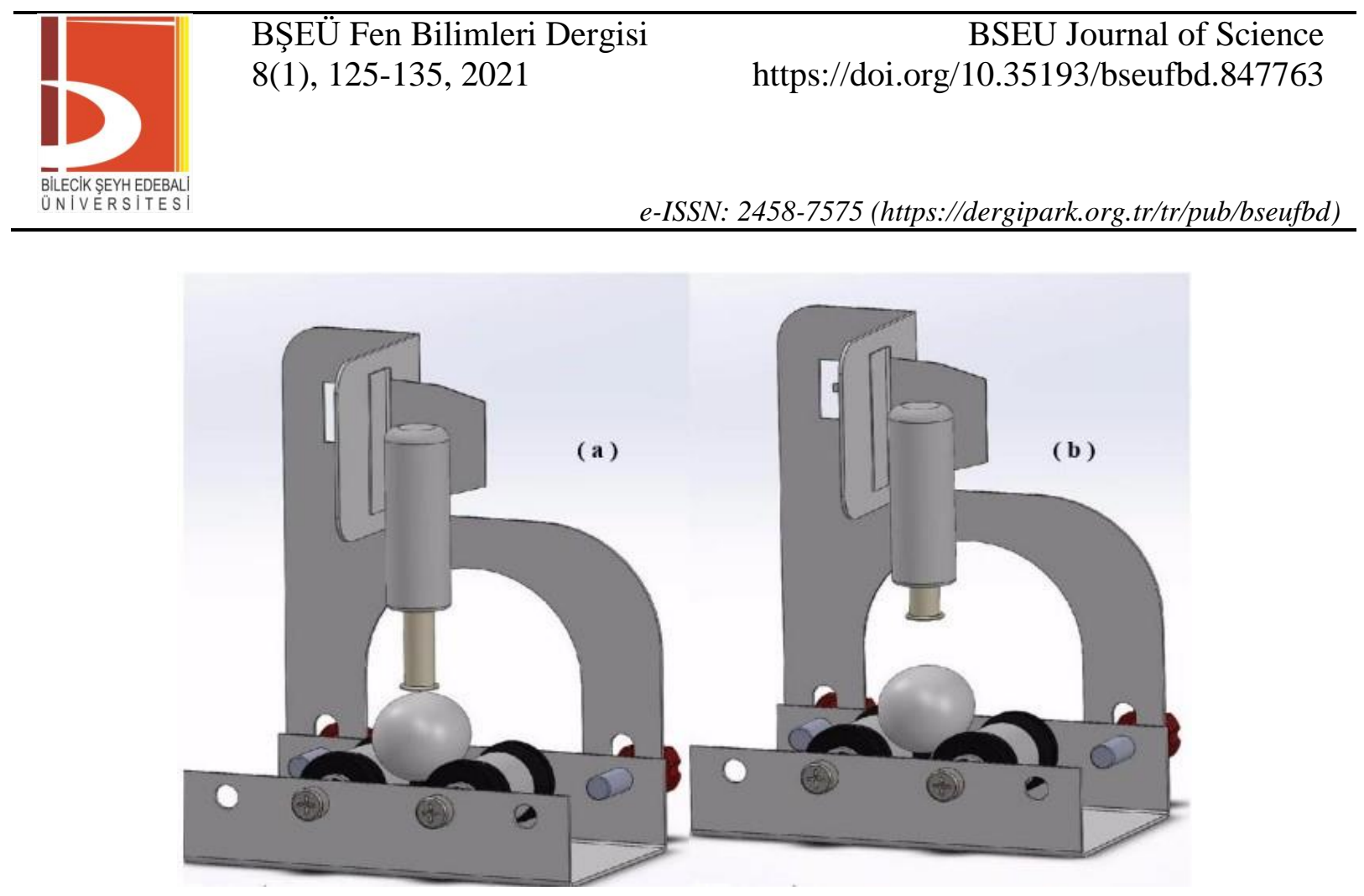

Şekil 3. Yumurtaya çarpma pozisyonu (a), başlangıç pozisyonu (b)

\section{C. İşlemsel Yükselteç ve Sürücü Devresi}

Yumurta kabuğundan elde edilen akustik sinyalleri kuvvetlendirmek ve mekanik etki ünitesinin kontrolü için, L293D sürücü entegresi, LN358N kuvvetlendirici entegresi ve devre için gerekli pasif devre elemanları kullanılarak tasarlanan kart Şekil 4'de gözükmektedir.

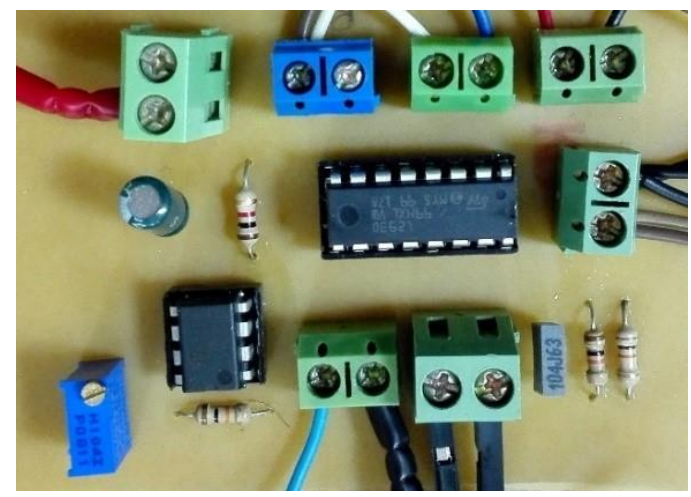

Şekil 4. Sinyal kuvvetlendirici ve kontrol devresi

\section{Veri Toplama Programı}

Çalışmada ihtiyaç duyulan veri setinin oluşturulması için LABVIEW [27] ortamında yazılan veri toplama programı Şekil 5'te verilmiştir. Bu programda veri al butonuna basıldığında belirtilen örnekleme süresi esas alınarak yumurtaya uygulanan mekanik etki sonucu oluşan ses sinyalinin verisi alınmaktadır. 


\begin{tabular}{|c|c|c|}
\hline & $\begin{array}{l}\text { BŞEÜ Fen Bilimleri Dergisi } \\
8(1), 125-135,2021\end{array}$ & $\begin{array}{r}\text { BSEU Journal of Science } \\
\text { https://doi.org/10.35193/bseufbd.847763 }\end{array}$ \\
\hline ERS & & 2458-7575 (https://dergipark.org.tr/tr/pub/bseufbd) \\
\hline
\end{tabular}

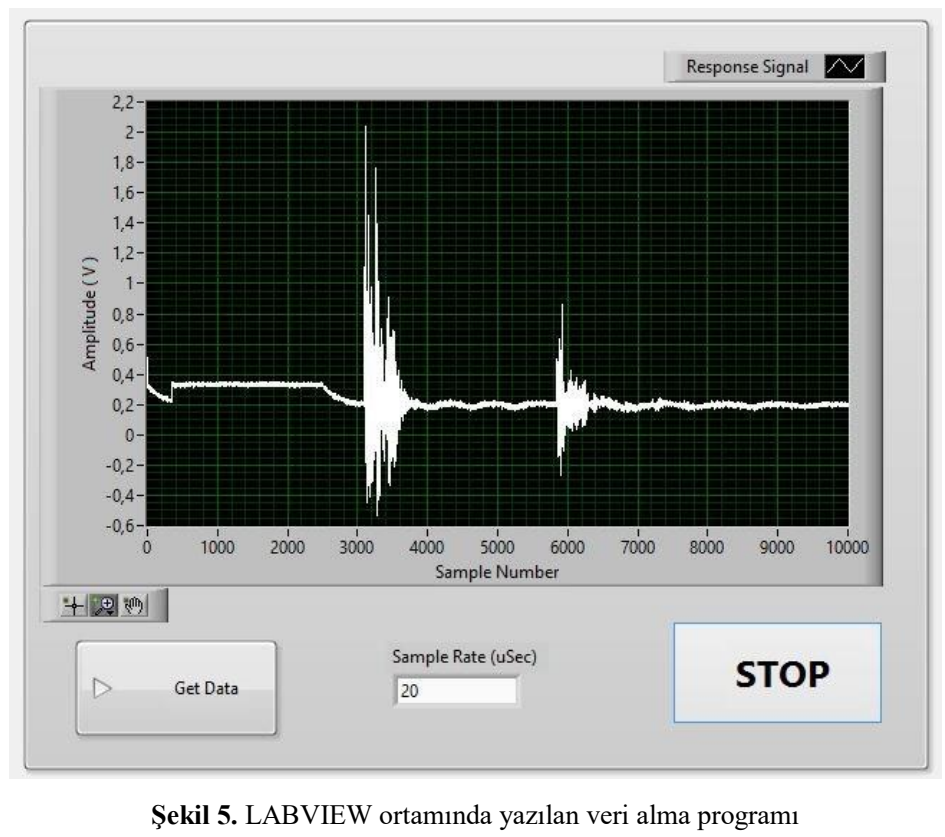

\section{E. Özellik Vektörünü̈n Çıkartımı}

Sistemden her bir yumurta için $50 \mathrm{kHz}$ örnekleme frekansında 0.2 sn boyunca 10000 adet veri alınmıştır. LabVIEW programında 116 adet yumurta verisini barındıran bir veri seti oluşturulmuştur. Bundan sonraki işlemler Matlab programında gerçekleştirilmiştir. Sinyalin bu haliyle kullanılması hem işlem sürecinin uzamasına hem de yapay zekâ yöntemiyle yapılacak yumurta kabuğunun çatlak/sağlam olması durumunun sınıflandırma başarımını düşürecektir. Mekanik sistemdeki bobine bir yönde enerji verildiğinde içerisindeki pim çıkarak yumurtaya vurmakta ve bobine diğer yönde enerji uygulanması durumunda pim geri ilk konumuna gelmektedir. Şekil 5 'te verilen bir yumurta verisi incelendiğinde bobin içerisindeki pimin yumurtaya vurması durumunda ve kapanması durumunda alınan ses sinyalinde önemli değişiklikler meydana gelmektedir. Pimin yumurtaya vurmasıyla ses sinyalinin genliğinde ani bir artış gözlemlenerek oluşan salınım zamanla sönümlenmektedir. Kabuğu çatlak/sağlam yumurtada salınım süresi değişkenlik göstermektedir. $0.75 \mathrm{~V}$ eşik değeri kullanılarak yumurtaya vurulma anı tam olarak tespit edilip bundan sonraki 680 veri alınıp kullanılmıştır.

Dalgacık dönüşümü, sinyaldeki keskin yükselmeler ve süreksizlikleri tanımlamada çok etkili bir yöntemdir [28]. Dalgacık dönüşümünün özelliğini doğal olarak tutan DPD hem zaman hem de frekans alanları içinde iyi bir yerelleştirme özelliğine sahiptir. Durağan ve periyodik olmayan sinyallerin analizinde büyük bir başarım göstermektedir [29]. Sinyalden özellik çıkartımı için DPD kullanılmıştır. Böylece sinyalin düşük frekanslı yaklaşım ve yüksek frekanslı detay bileşenleri tespit edilmiştir. Ana dalgacık olarak Daubechies 4 (db4) dalgacığı kullanılmıştır [30]. İkinci seviye DPD uygulanarak 1x680 boyutunda farklı frekans bantlarına ait dört farklı sinyal elde edilir. Gerek bu verilerin boyutunu azaltmak gerekse durağan olmayan bir sinyal içerisindeki düzensizlik derecesini ölçmek için bu sinyallerin entropisi hesaplanır. Çeşitli entropi hesaplama yöntemleri mevcut olup bu çalışmada norm entropi tercih edilmiştir. Matematiksel ifadesi denklem (1)'deki gibidir [31];

$$
\mathrm{E}(\mathrm{s})=\sum_{\mathrm{i}}\left|\mathrm{S}_{\mathrm{i}}\right|^{\mathrm{p}} \quad 1 \leq \mathrm{p}<2 \mathrm{E}(\mathrm{s})=\sum_{\mathrm{i}}\left|\mathrm{S}_{\mathrm{i}}\right|^{\mathrm{p}} \quad 1 \leq \mathrm{p}<2
$$

Özellik vektörümüz $1 \mathrm{x} 4$ boyutuna gelmiştir. Verilerin kaydı sırasında daha az yer kapladığ 1 gibi sınıflandırıcının da birbiriyle yakın ilişkili olan daha az veriyle işlem yapması sınıflandırma başarımını arttıracaktır. Özellik vektörünün çıkarımına ilişkin adımlar detaylı olarak Şekil 6'da verilmiştir. 


\begin{tabular}{|c|c|c|}
\hline & $\begin{array}{l}\text { BŞEÜ Fen Bilimleri Dergisi } \\
8(1), 125-135,2021\end{array}$ & $\begin{array}{r}\text { BSEU Journal of Science } \\
\text { https://doi.org/10.35193/bseufbd.847763 }\end{array}$ \\
\hline $\begin{array}{l}\text { BulLECCIKSEYH EDEBALL } \\
\text { ONIVERSITES }\end{array}$ & & 2458-7575 (https://dergipark.org.tr/tr/pub/bseufbd) \\
\hline
\end{tabular}

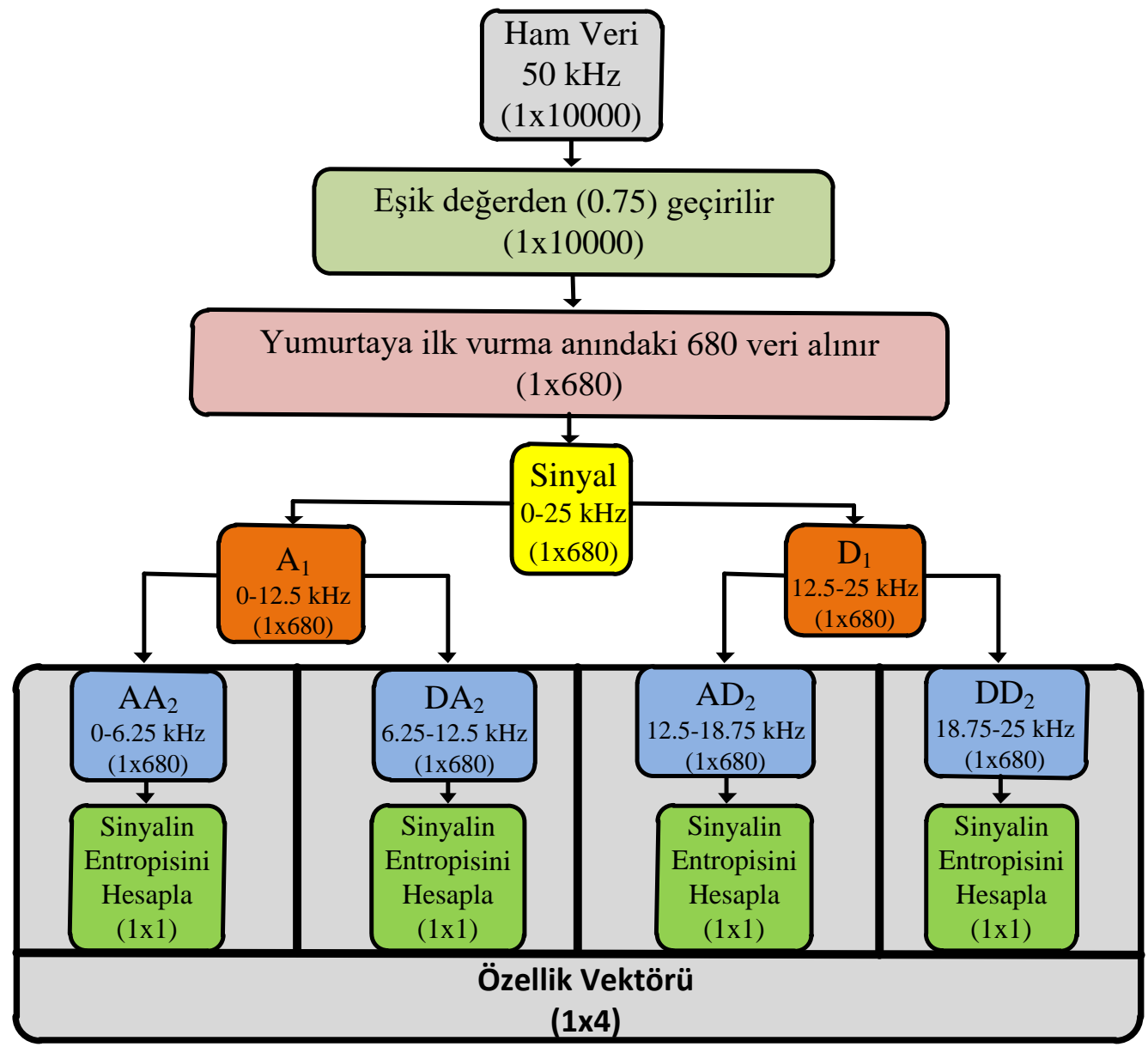

Şekil 6. Özellik vektörünün çıkarımı

\section{F. YSA ile Çatlak Yumurtanın Tespiti}

İnsan beyninin çalışma mantığından esinlenerek YSA'lar oluşturulmuştur. Öncelikli olarak eldeki verilere göre ağ eğitilmekte ve sonrasında yeni bir durumla karşılaşıldığında bir yargıya varabilmektedir. Temel olarak bir YSA giriş katmanı, gizli katman ve çıkış katmanından oluşmaktadır. Ağın giriş ve çıkış sayısı giriş ve çıkış katmanındaki nöron sayısını belirlerken, gizli katman sayısını ve katmanlardaki nöron sayısı kullanılan veri setine göre değişkenlik göstermektedir. YSA modeli, MATLAB programı içerisinde yer alan Neural Network FittingTool (nftool) aracı kullanılarak oluşturulmuştur. Özellik vektörünün boyutu 1x4 olduğundan giriş katmanında 4 nöron bulunmaktadır. Gizli katmanda 10 nöron seçilirken tek çıkışımız olduğundan çıkış katmanında 1 nöron bulunmaktadır. Çıkışın değeri yumurta kabuğunun çatlak olması durumunda 0 , sağlam olması durumunda 1 olacak şekilde etiketlendirilmiştir. 100 yumurta verisi içerisinden rastgele olarak ağın eğitimi için 80, değerlendirilmesi için 10 ve test edilmesi için ise 10 adedi kullanılmıştır. Levenberg-Marquardt eğitim algoritması ile ileri beslemeli geri yayılımlı ağın eğitimi gerçekleştirilmiştir. Hazırlanan YSA modelinin ayrıntıları Şekil 7' de verilmiştir. 


\begin{tabular}{|c|c|c|}
\hline & $\begin{array}{l}\text { BŞEÜ Fen Bilimleri Dergisi } \\
8(1), 125-135,2021\end{array}$ & $\begin{array}{r}\text { BSEU Journal of Science } \\
\text { https://doi.org/10.35193/bseufbd } 847763\end{array}$ \\
\hline ERS & & 2458-7575 (https://dergipark.org.tr/tr/pub/bseufbd) \\
\hline
\end{tabular}

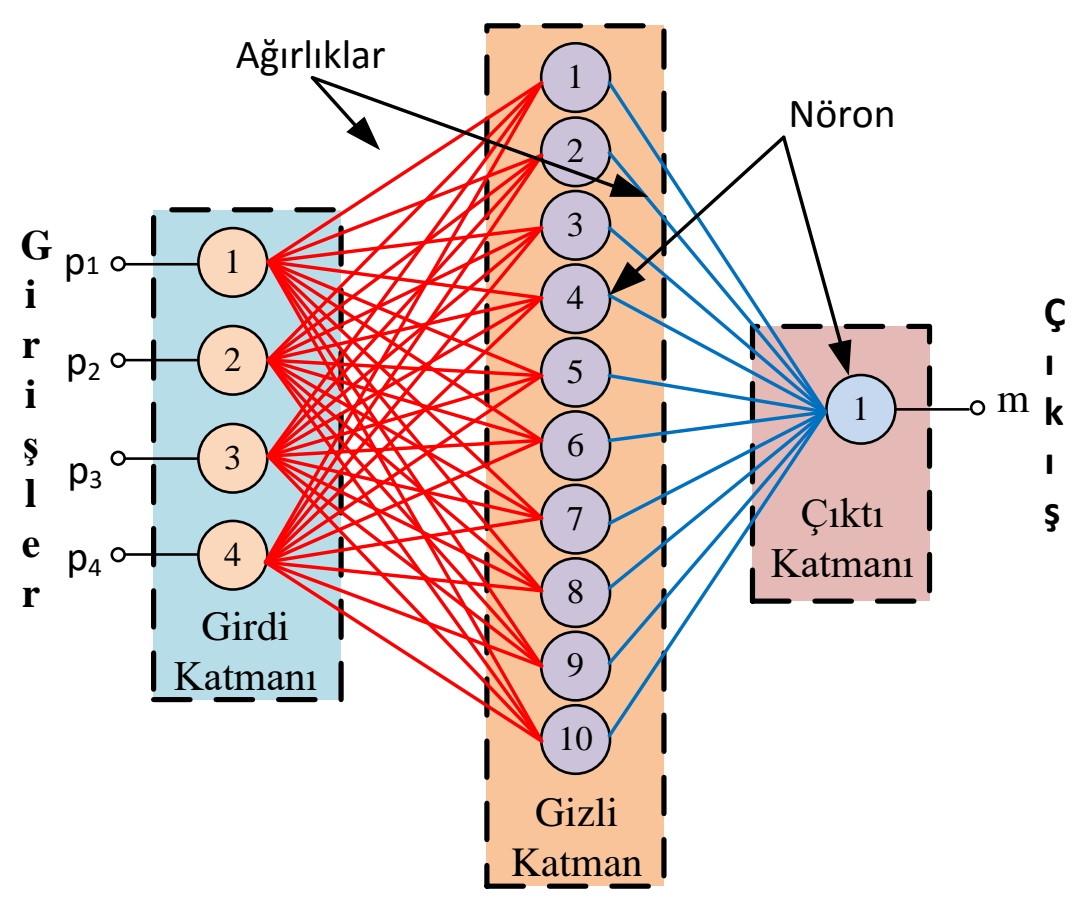

Şekil 7. Hazırlanan YSA modelinin yapısı

Eğitimi gerçekleştirilen YSA'nın değerlendirmesi ortalama karesel hata (MSE) ve regresyon değerine $\left(\mathrm{R}^{2}\right)$ göre yapılmaktadır. Ağın iyi eğitilmesi için MSE değerinin sıfıra ve $\mathrm{R}^{2}$ değerinin bire yakın olması beklenmektedir. Eğitimi yapılan YSA modelinin MSE ve $\mathrm{R}^{2}$ değerleri Tablo 1'de detaylı olarak verilmiştir.

Tablo 1. Hazırlanan YSA modelinin eğitim sonuçları

\begin{tabular}{lccc}
\hline & Örnek Sayıs & MSE & $\mathbf{R}^{\mathbf{2}}$ \\
\hline Eğitim & 80 & $8.92112 \mathrm{e}-16$ & $9.99999 \mathrm{e}-1$ \\
Değerlendirme & 10 & $3.32617 \mathrm{e}-16$ & $9.99999 \mathrm{e}-1$ \\
Test & 10 & $1.36625 \mathrm{e}-15$ & $9.99999 \mathrm{e}-1$ \\
\hline
\end{tabular}

III. BULGULAR VE TARTIŞMA

$50 \mathrm{kHz}$ örnekleme frekansında yumurta kabuğunda mekanik etki ile oluşturulan ses sinyalleri pim üzerindeki mikrofon yardımıyla 0.2 sn boyunca 10.000 adet veri olarak kayıt altına alınmıştır. Kabuğu çatlak olan 50 ve sağlam olan 50 yumurta olmak üzere 100 yumurtaya ait bir veri seti oluşturulmuştur. Bir yumurtaya ait 10.000 veriyi azaltmak içerisindeki asıl darbe anı ve sonrasındaki sönümlenme süresince verileri tespit etmek için $0.75 \mathrm{~V}$ eşik değeri kullanılmıştır. Eşik değerinden sonraki 680 veri alınarak öncelikli olarak sinyal işleme metotlarından biri olan DPD uygulanmıştır. Farklı frekans bant aralı̆̆ına sahip bileşenlerin entropi değerleri hesaplanarak özellik vektörünün boyutu $1 \times 4$ olarak düşürülmüsştür. Veri setindeki 50 çatlak ve 50 sağlam yumurta verisi kullanılarak YSA eğitim işlemi gerçekleştirilmiştir. YSA çıkışında sağlam yumurta için 1 değeri alınırken çatlak yumurta için ise tam 0 değeri değil de sıfıra yakın bir değer elde edilmiştir. Çıkarımı yapılan özellik vektörünün yumurtanın kabuğunun çatlak/sağlam olması durumundaki değişimi ve YSA'nın tahmini çıkış değerlerinin durumu Tablo 2'de gerçek değerlerle karşılaştırmalı olarak verilmiştir. Bu veriler, YSA tarafından başlangıçta 100 yumurta içeren veri seti içerisinden rastgele seçilen 10 adet test verisinden örnek olarak alınan üç adet kabuğu çatlak ve üç adet kabuğu sağlam yumurtaya ait verilerdir. 


\begin{tabular}{|c|c|c|}
\hline & $\begin{array}{l}\text { BŞEÜ Fen Bilimleri Dergisi } \\
8(1), 125-135,2021\end{array}$ & $\begin{array}{r}\text { BSEU Journal of Science } \\
\text { https://doi.org/10.35193/bseufbd.847763 }\end{array}$ \\
\hline & & 2458-7575 (https://dergipark.org.tr/tr/pub/bseufbd) \\
\hline
\end{tabular}

Tablo 2. Çıkarımı yapılan özellik vektörleri ve YSA modelinin tahmini çıkış değerleri

\begin{tabular}{cccccccc}
\hline & \multicolumn{3}{c}{ Çatlak Yumurta } & \multicolumn{3}{c}{ Sağlam Yumurta } \\
\hline & 245.0170 & 132.2851 & 212.3664 & 65.2689 & 134.7160 & 155.6506 \\
Özellik Vektörü & 1.4694 & 0.4515 & 0.7624 & 0.0731 & 0.0494 & 0.0381 \\
& 0.0279 & 0.0209 & 0.0161 & 0.0088 & 0.0063 & 0.0050 \\
& 0.0359 & 0.0257 & 0.0375 & 0.0149 & 0.0152 & 0.0091 \\
\hline Gerçek Çıkış & 0 & 0 & 0 & 1 & 1 & 1 \\
\hline Tahmini Çıkış & $2.8985 \mathrm{e}-08$ & $-9.9765 \mathrm{e}-08$ & $1.6064 \mathrm{e}-08$ & 1 & 1 & 1 \\
\hline
\end{tabular}

Yumurta kabuğunun çatlak olması durumunda, sağlam olması durumuna göre özellik vektörünü oluşturan özellikle 2. ve 3. parametrelerin değerleri daha yüksektir. YSA modeli çıkışında çatlak yumurtaya ait olan 0 etiketinin tam olarak alınabilmesi için 1e-6 değerinde bir eşikten geçirilmesine karar verilmiştir. Böylece ağın çıkışında gerçek değerlerle birebir aynı etiketler gözlemlenmiştir.

Referans [24] incelendiğinde $22050 \mathrm{~Hz}$ örnekleme frekansında aldıkları 500 veriyi çalışmalarında kullanmışlardır. Elde edilen sinyale db7 dalgacığını kullanarak 7. seviyeden ayrık dalgacık dönüşümü uygulamışlardır. Elde edilen bileşenlerin enerji değerlerini hesaplayarak 1x8 boyutunda özellik vektörünü elde etmişlerdir. Özellik vektörü verilerini Bayes teoremine dayalı olarak oluşturdukları ayrık modele girerek yumurta kabuğunun çatlak/sağlam olması durumunu farklı dokunma noktalarına göre \%95'e varan başarım oranıyla tespitini sağlamışlardır. Bu çalışmada ise, yumurta kabuğundan $50 \mathrm{kHz}$ örnekleme frekansında 10.000 adet veri alınıp, $0.75 \mathrm{~V}$ eşik değerinden geçirilip, toplamda 680 veri kullanılmıştır. 2. seviyeden DPD uygulanıp elde edilen bileşenlerin entropisi hesaplanarak, $1 \times 4$ boyutunda özellik vektörü elde edilmiştir. Özellik vektörünün etkinliğini göstermek amacıyla YSA ile yapılan tahmin işlemlerinde $\% 100$ başarım elde edilmiştir.

Ağın eğitim işlemi sürecine dâhil edilmeyen eğitim/değerlendirme/test verilerinden hariç olarak 16 adet yumurta verisiyle kullanılan özellik vektörü ve sınıflandırıcının doğruluğu denenmiş ve başarım \%100 olarak bulunmuştur (Şekil 8). Elde edilen sonuçlar çıkartımı yapılan özellik vektörünün yumurta kabuğundaki çatlakların tespitinde etkili olduğunu göstermektedir.

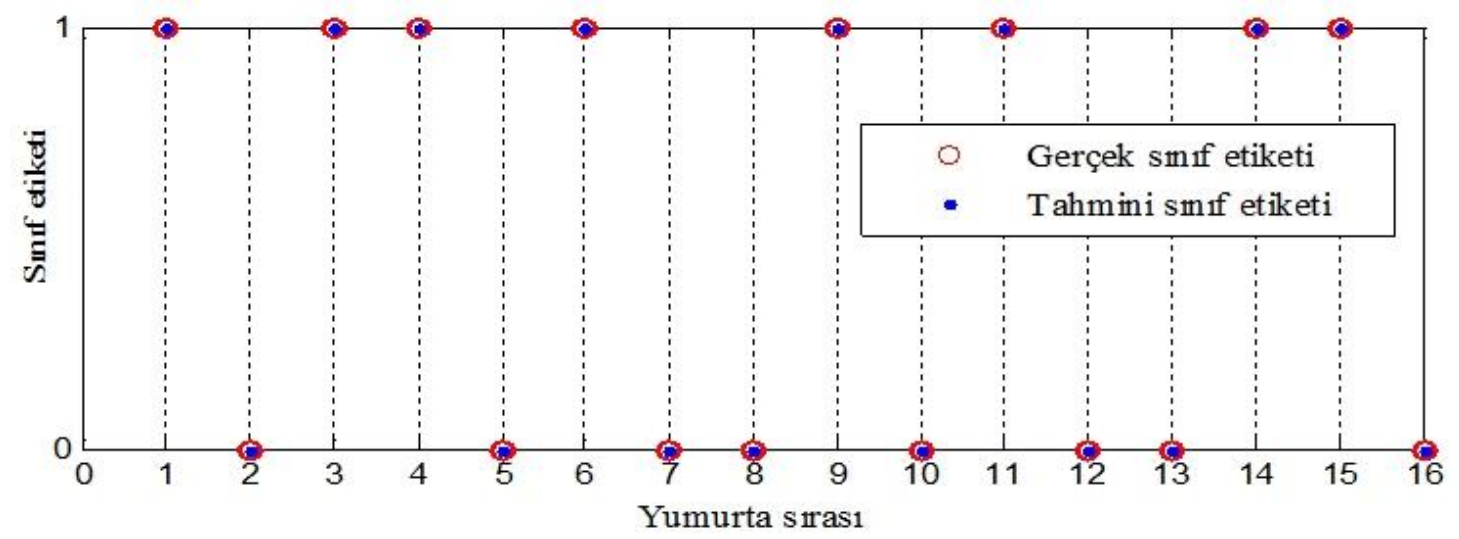

Şekil 8. Harici değerlendirme veri sonuçları

Çalışma süresince kullanılan laptopun özellikleri; işlemcisi Intel Core i7 740QM @ 1.73GHz, ram 6 GB DDR3 $1333 \mathrm{MHz}$ ve 500 GB 5400 RPM hızındaki hard diske sahiptir. Yumurta çatlak verilerinin temini için tasarlanan mekanik sistemden verinin alınması için 0.2 sn gerekli iken bu verinin işlenip özellik vektörünün çıkartılıp sınıflandırıı tarafından çatlak/sağlam durumunun tespiti için yaklaşık $0.016 \mathrm{sn}$ gibi bir süre gereklidir. Hem mekanik sistem hem de yazılımlar ile doğrudan bir yumurtanın çatlak/sağlam olması durumu yaklaşık olarak 0.216 sn' de tespit edilebilmektedir. Endüstriyel uygulamalarda rahatlıkla kullanılabilecek bir sürede sistem sonuç vermektedir. 


\section{IV.SONUCLLAR}

Yumurtanın üretildiği andan paketleme aşamasına gelene kadarki süreçte kabuğunda çatlaklar meydana gelebilmektedir. Bu çatlaklardan zararlı mikro organizmalar içerişine girebileceği gibi havayla temastan dolayı kısa sürede yumurtanın bozulmasına sebebiyet verecektir. Çatlaklar bazen gözle kolayca ayırt edilebilirken bazen de mikro boyutta olup ayırt edilememektedir. Artan yumurta talebinin karşılamak için bu işlemin hızlı ve yüksek doğruluk oranı ile gerçekleştirilebilmesi gerektiğinden sinyal işleme ve makine öğrenme tabanlı sistemler tercih edilir. Bu çalışmada mekanik sistem vasıtasıyla yumurta kabuğuna zarar vermeyecek şiddette bir darbe uygulanıp akustik ses sinyalleri kayıt altına alınıp sinyal işleme ve yapay zekâya dayalı olarak kabuğun sağlam/çatlak durumu tespit edilmeye çalışılmıştır. Öncelikli olarak darbe anı ve sonrasındaki salınım kısmını veri içerisinden çıkartmak amacıyla bir eşik değer ve sonrasındaki 680 veri alınarak kullanılmıştır. Akustik sinyaldeki bize gerekli olan kısım alındıktan sonra sırasıyla sinyale DPD uygulanmış ve elde edilen bileşenlerin entropi değeri hesaplanarak $1 \times 4$ boyutunda özellik vektörümüz elde edilmiştir. YSA bu verilerle eğitilerek çıkışında 0 -çatlak kabuk 1-sağlam kabuk bilgisi elde edilmektedir. Mekanik sistemden veri alınıp işlenip özellik vektörünün elde edilmesi ve YSA ile kabuğun çatlak/sağlam durumunun tespiti yaklaşık olarak 0.216 sn gibi kısa bir sürede denenen tüm verilerle $\% 100$ doğruluk oranında tespit edilmiştir. Endüstriyel uygulamalar için elverişlidir.

\section{KAYNAKLAR}

[1] Sing, M. \& Brar, J. (2016). Egg Safety in the Realm of Preharvest Food Safety. Microbiol. Spectr., 4 (4),114, doi: 10.1128/microbiolspec.PFS-0005-2014.

[2] Mazzuco, H. \& Bertechini, A. G. (2014). Critical points on egg production: causes, importance and incidence of eggshell breakage and defects. Ciência e Agrotecnologia, 38 (1), 7-14.

[3] Van Mourik, S., Alders, B. P. G. J., Helderman, F., van de Ven, L. J. F. \& Koerkamp, P. G. (2017). Predicting hairline fractures in eggs of mature hens. Poultry science, 96(6), 1956-1962.

[4] Rycroft, J. P. A. N. \& Gregory, N. G. (2009). Hazards with cracked eggs and their relationship to egg shell strength. J. Sci. Food Agric., 89 (2), 201-205.

[5] Öztürk, N. (2014). Görüntü işleme teknikleri ile beyaz yumurtalar üzerindeki yumurta kabuğu kusurlarının algılanması. (Y. Lisans Tezi), Karadeniz Teknik Üniversitesi, Fen Bilimleri Enstitüsü / Elektrik-Elektronik Mühendisliği ABD, Trabzon.

[6] Abdullah, M. H. Nashat, S. Anwar, S. A. \& Abdullah, M. Z. (2017). A framework for crack detection of fresh poultry eggs at visible radiation Comput. Electron. Agric., 141, 81-95.

[7] Fang, W. \& Youxian, W. (2011). Detecting preserved eggshell crack using machine vision. 2011 International Conference of Information Technology, 2011, Nanjing, 62-65.

[8] Omid, M. Soltani, M. Dehrouyeh, M. H. Mohtasebi, S. S. \& Ahmadi, H. (2013). An expert egg grading system based on machine vision and artificial intelligence techniques. J. Food Eng., 118 (1), 70-77, doi: 10.1016/J.JFOODENG.2013.03.019.

[9] Wang, F. Zhang, S. \& Tan, Z. (2017). Non-destructive crack detection of preserved eggs using a machine vision and multivariate analysis. Wuhan Univ. J. Nat. Sci., 22 (3), 257-262.

[10] Wu, L. Wang, Q. Jie, D. Wang, S. Zhu, Z. \& Xiong, L. (2018). Detection of crack eggs by image processing and soft-margin support vector machine. J. Comput. Methods Sci. Eng., 18 (1), 21-31.

[11] Orlova, Y. Linker, R. \& Spektor, B. (2012). Expansion of cracks in chicken eggs exposed to sub-atmospheric pressure. Biosyst. Eng., 112, (4), 278-284.

[12] Lawrence, K. C. Yoon, S. C. Jones, D. R. Heitschmidt, G. W. Park, B. \& Windham,W. R. (2009). Modified pressure system for imaging egg cracks. Trans. ASABE, 52 (3), 983-990.

[13] Lawrence, K. C. Yoon, S. C. Heitschmidt, G. W. Jones, D. R. \& Park, B. (2008). Imaging system with modified-pressure chamber for crack detection in shell eggs. Sens. Instrum. Food Qual. Saf., 2 (2), 116-122.

[14] Li, Y. Dhakal, S. \& Peng, Y. (2012). A machine vision system for identification of micro-crack in egg shell. J. Food Eng., 109 (1), 127-134, doi: 10.1016/J.JFOODENG.2011.09.024.

[15] Priyadumkol, J. Kittichaikarn, C. \& Thainimit, S. (2017). Crack detection on unwashed eggs using image processing. J. Food Eng., 209, 76-82.

[16] Wang, S. C. Ren, Y. L. Chen, H. Xiong, L. R. \& Wen, Y. X. (2004). Detection of cracked-shell eggs using acoustic signal and fuzzy recognition. Transations CSAE, 20 (4), 130-132.

[17] Lin, H. Zhao, J. Chen, Q. Cai, J. \& Zhou, P. (2009). Eggshell crack detection based on acoustic response and support vector data description algorithm. Eur. food Res. Technol., 230 (1), 95-100.

[18] Deng, X. Wang, Q. Chen, H. \& Xie, H. (2010). Eggshell crack detection using a wavelet-based support vector 
machine. Comput. Electron. Agric., 70 (1), 135-143, doi: 10.1016/J.COMPAG.2009.09.016.

[19] Zhao,Y. Wang, J. Lu, Q. \& Jiang, R. (2010). Pattern recognition of eggshell crack using PCA and LDA. Innov. Food Sci. Emerg. Technol., 11 (3), 520-525.

[20] Ding, T. Lu, W. Zhang, C. Du, J. Ding, W. \& Zhao, X. (2015). Eggshell crack identification based on Welch power spectrum and generalized regression neural network (GRNN). Food Sci, 36, 156-160.

[21] Wang, H. Mao, J. Zhang, J. Jiang, H. \& Wang, J. (2016). Acoustic feature extraction and optimization of crack detection for eggshell, J. Food Eng., 171, 240-247.

[22] Strnková, J. \& Nedomová, Š. (2013). Eggshell Crack Detection Using Dynamic Frequency Analysis. MENDELNET, 2013, Brno, 603-608.

[23] Jin, C. Xie, L. \& Ying, Y. (2015). Eggshell crack detection based on the time-domain acoustic signal of rolling eggs on a step-plate. J. Food Eng., 153, 53-62, doi: 10.1016/J.JFOODENG.2014.12.011.

[24] Li, P. Wang, Q. Zhang, Q. Cao, S. Liu,Y. \& Zhu, T. (2012). Non-destructive Detection on the Egg Crack Based on Wavelet Transform. IERI Procedia, 2, 372-382, doi: 10.1016/J.IERI.2012.06.104.

[25] Sun, L. Feng, S. Chen,C. Liu, X. \& Cai, J. (2020). Identification of eggshell crack for hen egg and duck egg using correlation analysis based on acoustic resonance method. J. Food Process Eng., 43 (8), 1-9.

[26] Wikipedia. (2020). CompactRIO. https://en.wikipedia.org/wiki/CompactRIO, (Ekim 09, 2020).

[27] Wikipedia. (2020). LabVIEW. https://tr.wikipedia.org/wiki/LabVIEW, (Ekim 09, 2020).

[28] Xiong, S. Zhou, H. He, S. Zhang, L. Xia, Q. Xuan, J. \& Shi, T. (2020). A novel end-to-end fault diagnosis approach for rolling bearings by integrating wavelet packet transform into convolutional neural network structures. Sensors, 20, doi:10.3390/s20174965.

[29] Chen, G. Li, Q. Li, D. Wu, Z. \& Liu, Y. (2019). Main frequency band of blast vibration signal based on wavelet packet transform. Applied Mathematical Modelling, 74, 569-585.

[30] Dodia, S. Edla, D. R. Bablani, A. Ramesh, D. \& Kuppili, V. (2019). An efficient EEG based deceit identification test using wavelet packet transform and linear discriminant analysis. Journal of neuroscience methods, 314, 31-40.

[31] Uyar, M. (2008). Güç kalitesindeki bozulma türlerinin akıllı örüntü tanıma yaklaşımları ile belirlenmesi. (Doktora Tezi), Fırat Üniversitesi, Fen Bilimleri Enstitüsü / Elektrik-Elektronik Mühendisliği ABD, Elazığ. 